Sylvia Debossan Moretzsohn:

\title{
Contra o capital, em nome da humanidade: o sentido ético e político da luta pelo direito à informação
}

\author{
Against capital, in the name of humanity: the ethical and political sense of the fight for the right \\ to information
}

\begin{abstract}
:
No momento em que as contradições do capitalismo empurram a humanidade para o limiar da barbárie, a formulação de alternativas é uma urgência que diz respeito à própria sobrevivência da espécie. Mas as pessoas precisam saber que essas alternativas existem, para entender que vale a pena lutar por elas. Comandado pelos grandes interesses do capital, entretanto, o complexo das infotelecomunicações bloqueia essas possibilidades, ao mesmo tempo em que realiza seu trabalho sistemático de disseminação ideológica. A partir desses argumentos, e orientado pela perspectiva ética da emancipação humana à qual Marx dedicou sua vida, este artigo aponta o caráter ético - e politico - da luta pelo direito à informação e à voz pública, e a prioridade no enfrentamento do poder das empresas de infotelecomunicações. Mostra os problemas dessa luta na sociedade brasileira, herdeira da "cultura do silêncio". Discute, também, as ilusões de liberdade recorrentes diante das novas tecnologias. E procura demonstrar por que a ética é incompatível com um sistema que transforma pessoas em mercadorias.
\end{abstract}

As the contradictions of capitalism push humanity to the brink of barbarism, the formulation of alternatives is an urgency that concerns the very survival of the species. But people need to know that these alternatives exist, to understand that it is worth fighting for them. Commanded by the great interests of capital, however, the infotelecommunications complex blocks these possibilities, while at the same time doing its systematic work of ideological dissemination. From this approach, and guided by the ethical perspective of human emancipation to which Marx dedicated his life, this article points out the ethical - and political - character of the struggle for the right to information and to public voice, and the priority of confronting the powerful infotelecommunication corporations. It shows the problems of this struggle in Brazilian society and its "culture of silence" tradition. It also discusses the recurring illusions of freedom in the face of new technologies. And it seeks to demonstrate why ethics is incompatible with a system that transforms people into commodities.

\section{Agenda:}

A ética na perspectiva marxista ...................................................................................... 107

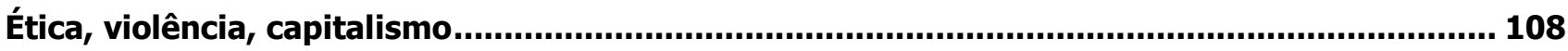

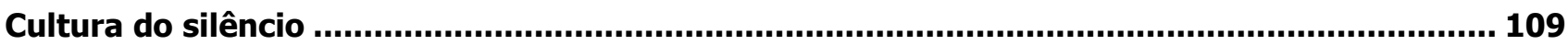

A internet como fetiche e as potencialidades e ilusões das redes.............................................. 110 


\section{Author:}

Prof. Dr. Sylvia Debossan Moretzsohn:

- Instituto de Arte e Comunicação Social, Universidade Federal Fluminense. Rua Lara Vilela, 126. 24510.590. São Domingos, Niterói, Brasil.

- $\square$ sylviamoretz@uol.com.br

- Relevant publications:

- Pensando contra os fatos. Jornalismo e Cotidiano: do senso comum ao senso crítico. Rio de Janeiro: Revan, 2007, 304p.

- O "repórter infiltrado" e a câmera oculta: repensando problemas éticos e epistemológicos para a prática do jornalismo. In: Edson Dalmonte. (Org.). Teoria e prática da crítica midiática. 1ed.Salvador: EdUFBA, 2013, p. 87-116. 
"Não há autonomia se não há voz própria e não pode haver um princípio político comum de autonomia se não há o direito público de formar uma voz livre" ${ }^{1}$. Ao prefaciar a coletânea de ensaios em que Venício A. de Lima discute a relação entre cultura do silêncio e democracia no Brasil, Juarez Guimarães sintetiza, nesta categórica afirmação, uma preocupação constante na obra de ambos: a dos necessários vínculos entre teoria democrática e liberdade de expressão, entre política e comunicação. Eles mesmos já haviam assinalado, em outro momento: "Política e comunicação são dimensões que não podem ser analiticamente isoladas sem se perder a
compreensão do próprio objeto que se investiga. (...)

Toda teoria que se pretende democrática, mas que não pensa as dimensões públicas da liberdade de expressão, as relações instituintes entre a constituição da cidadania e o direito à voz pública, esbarrará em impasses ou antinomias centrais. Toda teoria da comunicação que despolitiza o seu objeto, negando ou marginalizando as fundações políticas da comunicação que se faz em sociedade, está na verdade optando por conceber a liberdade de expressão como um direito que se privatiza ou que se realiza na ordem do privado, em geral mercantil ${ }^{\text {m. }}$.

O que importará para este artigo, entretanto, é a dimensão ética da defesa da autonomia baseada na livre expressão, articulada a uma política voltada para garanti-la. Consequentemente, a necessidade da luta para a realização desse projeto e a compreensão de que a luta ética é sempre, também, uma luta política.

Dessa forma, procuramos ampliar a abrangência de um debate que já acumula muito boas análises tanto a respeito das estratégias discursivas que distorcem, ocultam e fraudam as informações de circulação pública com suas nefastas consequências para a formação da opinião - quanto sobre as políticas de comunicação, com trabalhos que demonstram a necessidade do combate ao oligopólio no controle dos meios e de uma legislação que garanta a máxima dispersão da propriedade para promover a pluralidade de vozes essencial numa democracia.

A extensão da abordagem para o ambiente inaugurado com a internet permitirá reiterar a crítica, ainda pouco significativa no meio acadêmico, à ilusão de autonomia proporcionada pela tecnologia digital. $\mathrm{O}$ "maravilhamento" que Álvaro Vieira Pinto 3 observou no comportamento humano diante de todo avanço da técnica ignora, ou finge ignorar, a articulação das forças políticas para a ocupação desses novos espaços de formação de opinião. Assim, reproduz-se, no meio virtual, precisamente a mesma lógica de poder que sufoca as "outras falas", embora com a aparência de abertura à expressão espontânea e "horizontal" dos indivíduos indiferenciados.

Se antes da chamada "revolução digital" já era visível a centralidade da mídia na formação de opinião - e na reprodução e consolidação da ideologia dominante -, hoje esse poder se ampliou exponencialmente, como assinala Marco Schneider, com a constituição do "gigantesco complexo tecno-empresarial" que compõe as infotelecomunicações (ITCs) ${ }^{4}$. Enfrentá-lo é a tarefa prioritária, pois é, duplamente, pela consciência e pelas emoções que se pode mobilizar as pessoas para a luta. A urgência é dada pelo tempo que vivemos: as contradições do mundo do capital nos empurram para o limiar da barbárie e põem em risco a própria sobrevivência da espécie.

\footnotetext{
${ }^{1}$ Guimarães, in Lima (2015), 15.

2 Lima e Guimarães (2013), 10-11.

${ }^{3}$ Pinto (2005).

${ }^{4}$ Schneider (2015), 45.
} 
Como diz Schneider, nenhuma transformação profunda da sociedade é possível sem a mobilização das massas, "e as massas só podem ser mobilizadas se for possível demonstrar - racional e emocionalmente - que uma tal transformação é viável e desejável" ${ }^{\prime \prime}$. Em suma: não basta formular alternativas. É preciso que as pessoas saibam que elas existem, "tomem gosto" por essa possibilidade e "sintam essa urgência". Para tanto, seria preciso utilizar as ITCs a serviço do projeto emancipatório ${ }^{6}$. Como fazer isso se é tão gigantesca a engrenagem que lhes conforma o gosto e alimenta o senso comum que naturaliza a crença de que "não há alternativas" é a pergunta que continua sem resposta, mas justamente por isso é preciso insistir em formulá-la para buscar uma saída.

\section{A ética na perspectiva marxista}

Embora não trate formalmente do tema, Marx deu à sua obra um sentido ético muito preciso. Já a redação com a qual concluiu seu curso secundário indicava esse sentido. Nas Reflexões de um jovem sobre a escolha de uma profissão, em 1835, escreveu: "o guia que deve nos conduzir na escolha de uma profissão é o bemestar da humanidade e nossa própria perfeição". Seu trabalho como jovem jornalista na Gazeta Renana, quando investiu contra a nova legislação que passou a impedir os trabalhadores pobres de recolher galhos de madeira para aquecerem suas casas no inverno, alimentou sua indignação diante da injustiça e o levou a empreender, já em 1843, o esforço de uma crítica ao idealismo hegeliano e, posteriormente, ao empirismo de Feuerbach, para buscar no estudo da sociedade burguesa e de suas contradições as bases concretas para a formulação de uma teoria que orientasse a luta pela emancipação humana. É esse, aliás, o sentido da famosa $11^{\mathrm{a}}$ tese sobre Feuerbach - "os filósofos apenas interpretaram o mundo de diferentes maneiras; o que importa é transformá-/o's: contra a atitude contemplativa, a reflexão que conduzisse à ação, mas a uma ação voltada para a humanização do homem, como o comprovam sua obra e sua militância política.

Leandro Konder expõe a perspectiva ética que subjaz ao trabalho de Marx:

"A práxis é o conceito central da filosofia de Marx, (...) É a matriz de uma concepção original da história, uma concepção que, sendo materialista, reconhece o poder do sujeito de tomar iniciativas, fazer escolhas. Por isso, precisa de uma ética. Depende de valores que lhe permitam empenhar-se em projetos de transformação do mundo, na criação de um tipo melhor de sociedade, num futuro pelo qual valha a pena lutarm.

E, adiante:

"Para Marx, os valores constituem um fundamento essencial da práxis. A atividade própria do homem aquela em que ele se humaniza (a práxis) - é teleológica. É antecipadora, projetiva. Nada é absolutamente garantido, nada é imutável. Os próprios fundamentos das opções que vão se fazendo ao longo da vida pedem muitas vezes reexames, revisões" ${ }^{\prime 0}$.

\footnotetext{
${ }^{5}$ Schneider, idem, 218. Faço aqui uma ressalva no uso desse termo, no sentido que Marilena Chaui já assinalava em Cultura e democracia - o discurso competente e outras falas (ed. Moderna, 1984), pois "massa" sugere uma indiferenciação contraditória com a existência de sujeitos conscientes. Essa discussão, embora necessária, ultrapassa os limites deste artigo.

${ }^{6}$ Idem, ibidem.

7 Marx (1835)

8 Marx e Engels (2007), 535.

${ }^{9}$ Konder (2010), 16.

${ }^{10}$ Idem, 24.
} 
Precisamente porque "nada é absolutamente garantido", aliás, é preciso combater a concepção ainda prevalecente - e não só no senso comum -, seja por uma leitura inepta, seja por distorção deliberada, de que o pensamento marxiano é determinista.

Também Fábio Konder Comparato sustenta o sentido ético da crítica de Marx à sociedade burguesa:

"Essa análise devastadora, afinal, foi feita em nome do quê? Da fria e objetiva análise científica? Não é preciso conhecer em profundidade a obra de Marx para perceber que em cada linha de seus escritos (...) pulsa um insopitável movimento de indignação diante da injustiça social; e foi a denúncia sistemática dessa injustiça - não o exame pretensamente científico do capitalismo - que calou fundo no coração das massas".11

Entretanto, é preciso conhecer em profundidade a obra de Marx para corrigir certos persistentes equívocos a respeito dela. Em primeiro lugar, a referência ao exame "pretensamente científico" do capitalismo, que resultaria da "moda intelectual"12 daquele tempo, que, como se sabe, era o positivismo - e positivista era tudo o que Marx não era. Mas talvez daí decorra o erro fundamental de interpretação da relação entre base e superestrutura, derivado da vulgata marxista que Comparato, apesar de sua inegável erudição e do recurso a textos originais do pensador alemão, acaba repetindo: assim, supõe que a concepção de Marx sobre a ética como parte da estrutura jurídico-política - significava um "reducionismo (...) à condição de mero aparato ideológico"13.

Estamos aqui, no dizer de Ludovico Silva, diante da recorrente confusão entre metáfora e explicação teórica: se pensarmos, como ele sugere, num edifício e seus alicerces, trata-se de entender a metáfora de que é "a base ou o alicerce econômico [que] sustenta toda a enorme superestrutura ou edifício ideológico" ${ }^{\prime 4}$. Em suma, que essa "superestrutura" não existe no ar nem, muito menos, é quem produz os alicerces. Junte-se a isso o que ressalta Mészáros: estruturados dialeticamente, os conceitos fundamentais de Marx "simplesmente não podem ser entendidos fora da sua inter-relação dialética ( $e$, com frequência, aparentemente autocontraditória)"15.

\section{Ética, violência, capitalismo}

Qualquer ética pressupõe autonomia, isto é, a capacidade de o indivíduo formular suas próprias regras de ação. Mas como isto seria possível, se somos seres sociais e estamos submetidos a regras que não criamos?

Marilena Chaui argumenta que esse conflito entre a pretendida autonomia do sujeito e a heteronomia dos valores morais da sociedade em que ele vive se resolve se o agente assumir como seus esses valores: é como se ele próprio os tivesse instituído. É por isso que se pode dizer, de modo geral, que "o agente ético é pensado como sujeito ético, isto é, como um ser racional e consciente que sabe o que faz, como um ser livre que decide e escolhe o que faz, e como um ser responsável que responde pelo que faz" ${ }^{\prime \prime 6}$.

\footnotetext{
${ }^{11}$ Comparato (2006), 348.

12 Idem, 349.

${ }^{13}$ Idem, 348.

${ }^{14}$ Silva (2012), 55

15 Mészáros (2006), 19.

${ }^{16}$ Chaui (1998).
} 
Por que a violência é incompatível com a ética? Porque, segundo a filósofa, "trata seres racionais e sensíveis, dotados de linguagem e de liberdade como se fossem coisas, isto é, irracionais, insensíveis, mudos, inertes ou passivos".

Bastaria perguntar que tipo de sistema se estrutura de modo a tratar todas as pessoas como coisas, a desumanizá-las a ponto de reduzi-las a mercadorias, para concluirmos que o capitalismo é a expressão da mais radical violência e, desse ponto de vista, não pode ser compatível com nenhum tipo de ética. Se não é entendido dessa forma, se, pelo contrário, chega a ser glorificado, isso se deve ao sucesso do trabalho ideológico operado sobretudo pelas ITCs para consolidar a pior forma de alienação, que é a ilusão de consciência.

Uma ilusão facilmente produzida nesses tempos de (suposta) visibilidade total e avalanche informativa, pois a superexposição substitui a cegueira pela treva dos tempos pré-iluministas à cegueira pelo excesso de luz. Mas esta cegueira é mais grave, porque a luz em excesso sugere o pleno acesso à informação, que a treva escondia: assim, diante do que estava oculto, podíamos ser levados a saber que ignorávamos, e com isso despertar para a necessidade de saber; agora, pela aparência da visibilidade total, somos levados a ignorar que não sabemos, e nos consolamos nessa ilusão de saber ${ }^{17}$.

Não custa dizer que esse processo serve para convencer o indivíduo subjugado a pensar que é autônomo, como se vivesse no Admirável mundo novo de Huxley. E, assim, a naturalizar a submissão, que nem enxerga como tal.

Acrescente-se essa observação de Chaui, no mesmo artigo:

"as mudanças tecnológicas, a partir do momento em que a técnica deixa de ser ciência aplicada para tornar-se ciência cristalizada em objetos de intervenção humana sobre a natureza e a sociedade, transformam a tecnologia não só em forma de poder, mas sobretudo em força produtiva e parte integrante do capital, e essa transformação, feita exclusivamente sob a lógica do mercado, é sua transformação em lógica do poder como decisão sobre a vida e a morte em escala planetária".

Não seria exagero concluir, portanto, que a luta pela ética é uma luta essencialmente anticapitalista. E que a prioridade dessa luta é em torno das ITCs, dado o seu papel na produção de alienação.

\section{Cultura do silêncio}

Mas toda luta se dá num terreno concreto e o nosso terreno é o de um país de profunda herança colonial e escravocrata, onde não por acaso prevalece o patrimonialismo, que dita as regras práticas no cotidiano e na política apesar dos princípios constitucionais em contrário, exatamente porque entre nós vale a máxima "aos amigos, tudo, aos inimigos a lei". Como dizem Lima e Guimarães, a coincidência da formação de um moderno sistema de telecomunicações de alcance nacional justamente durante a última ditadura militar, organicamente vinculado a seus interesses políticos e econômicos, "só evidencia o quanto o regime de sua propriedade, sua concentração e sua regulação careceram na origem de um ethos democrático básico ${ }^{\text {"18 }}$.

É essa herança que torna tão importante a apreensão do conceito de "cultura do silêncio", para compreender a ausente, ou pelo menos muito débil e episódica, participação ativa dos cidadãos na vida pública.

\footnotetext{
17 Moretzsohn (2007), 29.

${ }^{18}$ Lima e Guimarães (2013), 16.
} 
O educador Paulo Freire elaborou esse conceito a partir de um dos famosos sermões do padre Antônio Vieira, no século XVII. Lima adverte que, naturalmente, jamais seria o caso de se acolher automaticamente uma intervenção religiosa - embora também evidentemente política, pois se tratava de um alerta ao vice-rei de Portugal sobre a situação da colônia - realizada em contexto tão díspare, mas de mostrar a fonte de inspiração que permitiu enxergar as raízes profundas do silenciamento da voz pública que perdura até hoje no Brasil e se estende pela América Latina, decorrente da estrutura de dominação colonial.

"A cultura do silêncio (...) caracteriza a sociedade a que se nega a comunicação e o diálogo e, em seu lugar, se Ihe oferecem 'comunicados', vale dizer, é o ambiente do tolhimento da voz e da ausência de comunicação, da incomunicabilidade ${ }^{\prime 9}$.

Se foi fortemente influenciado pela filosofia existencialista ${ }^{20}$, Freire carrega também a herança de Marx, em sua defesa da autonomia dos seres humanos, seu direito de autoexpressão e, notadamente, na valorização da práxis: segundo Lima, na concepção de Freire a interação entre reflexão e ação é "tão profunda que, se uma é sacrificada, ainda que em parte, a outra sofre imediatamente". Desse descompasso decorreriam o verbalismo - o sacrifício da ação - ou o ativismo - o sacrifício da reflexão ${ }^{21}$.

\section{A internet como fetiche e as potencialidades e ilusões das redes}

O surgimento de toda nova tecnologia costuma provocar teorizações apressadas e enganosas. Álvaro Vieira Pinto tratou de confrontá-las em seu denso estudo sobre o tema ${ }^{22}$. De início, rejeita aplicar ao mundo contemporâneo a denominação de "era tecnológica" - o que nos levaria a refletir sobre a fragilidade da definição do momento atual como "era da informação", aceita de modo tão automático e acrítico -, porque, afinal, não há era que não o seja: a tecnologia é produto do engenho humano, acompanha a história da humanidade. Pinto mostra que o "maravilhamento", no duplo sentido de deslumbramento e temor, do homem primitivo diante dos fenômenos da natureza se estende ao homem moderno diante da tecnologia, e o torna presa fácil de todo tipo de mistificação. A tecnologia aparece, assim, como algo externo ao mundo dos homens - ora uma ameaça, a máquina que conspurcaria uma idealizada essência humana, ora uma salvação. Em síntese, um fetiche, no clássico sentido da formulação marxiana ${ }^{23}$.

Daí também decorre o engano de que a internet é um ambiente "neutro", onde todos podem finalmente se expressar. O primeiro equívoco é quanto à neutralidade, que ignora os vários mecanismos acionados por quem controla esses espaços para direcionar a atividade do usuário. O segundo é quanto à ilusão de que, uma vez na grande rede, as pessoas finalmente se manifestarão livremente com sua "própria" voz, desconhecendo-se aí os processos de formação do senso comum. O terceiro é quanto à "horizontalidade", pois deveria ser claro que o mundo virtual reflete o presencial, sobretudo no que diz respeito às estratégias políticas de ocupação de espaços, com a agravante de que, nesse novo ambiente, o apelo à disseminação automática de informações facilita enormemente a difusão de boatos e mentiras e instaura a permanente incerteza. Sem contar a utilização

\footnotetext{
19 Lima (2015), 66.

20 Idem, 37.

${ }^{21}$ Freire, apud Lima, idem, 42.

22 Pinto (2005). O autor concluiu em 1973 sua exaustiva e profunda análise, no auge da excitação em torno do debate sobre os computadores e a cibernética. À parte certas ressalvas decorrentes de seu caráter datado, o livro, que só veio a ser publicado em 2005 , mantém a atualidade exatamente porque vai à raiz das questões e não se rende às especulações impressionistas lamentavelmente ainda corriqueiras inclusive no meio acadêmico.

23 Moretzsohn (2012).
} 
perversa que os usuários fazem do poder que passaram a ter de divulgar o que quiserem, sem se importarem com as consequências - portanto, sem qualquer preocupação ética ${ }^{24}$.

Importa perceber, em suma, que as possibilidades abertas pela internet não vão apenas - aliás, vão muito menos - no sentido da constituição de um novo senso comum, ancorado no pensamento crítico. Pois, no mundo do capital, é o capital que controla as redes. Certo, sempre existirão brechas por onde penetrar. Resta saber como alargá-las, numa sociedade domesticada pela cultura do silêncio.

\section{References}

CHAUI, Marilena. Ética e violência, in Teoria e Debate, ed. 39. São Paulo: Fundação Perseu Abramo, 1998. Disponivel em http://www.teoriaedebate.org.br/materias/sociedade/etica-e-violencia.

COMPARATO, Fábio Konder. Ética. Direito, moral e religião no mundo moderno. São Paulo: Companhia das Letras, 2006.

KONDER, Leandro. Em torno de Marx. São Paulo: Boitempo, 2010.

LIMA, Venício A. de. Cultura do silêncio e democracia no Brasil. Brasília: EdUnB, 2015.

LIMA, Venício A. de e GUIMARÃES, Juarez (org.). Liberdade de expressão. As várias faces de um desafio. São Paulo: Paulus, 2013.

MARX, Karl. Reflexões de um jovem sobre a escolha de uma profissão. 1835. https://www.marxists.org/portugues/marx/1835/08/16.htm

MARX, Karl. O Capital. Livro. 1. São Paulo: Boitempo, 2013.

MARX, Karl e ENGELS, Friedrich. A ideologia alemã. São Paulo: Boitempo, 2007.

MÉSZÁROS, István. O poder da ideologia. São Paulo: Boitempo, 2004.

MÉSZÁROS, István. A teoria da alienação em Marx. São Paulo: Boitempo, 2006.

MORETZSOHN, Sylvia. Pensando contra os fatos. Jornalismo e cotidiano: do senso comum ao senso crítico. Rio de Janeiro: Revan, 2007.

MORETZSOHN, Sylvia. As encruzilhadas da ética em tempos de "nova mídia". Anais do VII SBPjor. São Paulo, 2009. http://sbpjor.org.br/admjor/arquivos/sy/via_moretzsohn.pdf.

MORETZSOHN, SYIvia. O mundo "divertido": o fetiche da internet e a mobilização política nas redes sociais. Redesg, ano 1 , no 2012. https://periodicos.ufsm.br/REDESG/article/view/7310/pdf\#.WX_tUFGQzct

PINTO, Álvaro Vieira. O conceito de tecnologia. 2 vols. Rio de Janeiro: Contraponto, 2005.

SCHNEIDER, Marco. A dialética do gosto. Informação, música e política. Rio de Janeiro: Circuito/Faperj, 2015.

SILVA, Ludovico. O estilo literário de Marx. São Paulo: Expressão Popular, 2012.

${ }^{24}$ Desenvolvi esse tema, que envolve o direito à privacidade, em dois artigos: Moretzsohn $(2009,2013)$. 